\title{
Elaboration of a Model of Temporary Cooperation in Tourism' Destination Promotion A Systematic Literature Review
}

\author{
Maria Garbelli, PhD, Senior Lecturer \\ University of Milano Bicocca, Italy
}

Doi:10.19044/esj.2020.v16n28p55 URL:http://dx.doi.org/10.19044/esj.2020.v16n28p55

Submitted: 18 August 2020

Copyright 2020 Garbeli M.
OPEN ACCESS

\begin{abstract}
The literature considers cooperation as the best way for a region to achieve a competitive advantage in global, digital markets, and as taking a key role in achieving the promotion of a comprehensive, sustainable destination. In recent years, the body of research on cooperation in tourism has grown considerably, listing several opportunities for decreasing competitive pressure among local tourism actors, while gaining the superior advantages of collaboration. At the same time, the literature does not suggest particular models of cooperation for the tourism industry, as most are borrowed from the manufacturing industry, where cooperation seems widely used and further adapted for the tourism domain.

Through an in-depth systematic literature review, this paper matches the theories on cooperation in tourism with the concept of temporary cooperation, in order to adapt a model widely considered in several domains, the virtual enterprise (VE), to the peculiarities of the tourism industry. The adaptation is considered according to the particularities of the tourism industry, and especially when cooperation involves local tourism authorities in global turbulent markets. A cycle model consisting of nine-stages life was built, highlighting the main features of a temporary alliance among authorities: the pivotal role of the destination management organization, the relevance of information and communication technologies for the VE's operability, the short lifetime of the VE, and the destination's overall promotion.
\end{abstract}

Keywords: Temporary cooperation, virtual enterprise, information and communication technologies, destination management organization.

\section{Introduction}

Globalization has arisen rapidly, and hyper-competition seems to be the common situation in which the every industry around the globe faces, while the urgency for sustainable solutions demands rational uses of time, space, and resources (Garbelli, 2014). The tourism industry is not far from such needs: international and local authorities along with the literature are 
calling for a more sustainable approach to destination development, while recognizing a direct connection between cooperation and the achievement of sustainable development (Beritelli, 2011; Olsen, 2016).

Goal number 17 of the SDG focuses on "strengthen the means of implementation and revitalize the global partnership for sustainable development," revealing great attention on cooperation as a driver for achieving superior opportunities of sustainable development. Particularly, the goal develops the topic through the following comma: 17.16 enhance the global partnership for sustainable development complemented by multistakeholder partnerships that mobilize and share knowledge, expertise, technologies, and financial resources to support the achievement of sustainable development goals in all countries, particularly developing countries. 17.17 encourage and promote effective public, public-private, and civil society partnerships, building on the experience and resourcing strategies of partnerships (https://indicators.report/goals/goal-17).

The first comment clearly states a direct relationship with the achievement of sustainable development, but also entails the multiple resources to be shared among multiple stakeholders. With a focus on the multivariate nature of the partners involved, the succeeding comment promotes an effective partnership to be built upon. In fact, the management and marketing of tourism often requires a community effort due to its nature (Wilson et al., 2001), and collaboration represents a natural response to the marketing and management challenges of destinations (Wang et al., 2007; Wang, 2008).

Although the decision to cooperate with other entities appears to be a rising reality in tourism, it remains difficult to practice because of several constraints related to the dual nature of partners. Partners are defined as coopetitors as they partner around some goals, converging resources for reaching a common mission, but still compete simultaneously in other domains (Wilson et al., 2001; Frost \& Laing, 2018).

Nevertheless, a considerable number of research supporting cooperation in tourism has grown, from both global and local perspectives. As for the first, cooperation exists to provide new opportunities to sustain the highly competitive pressure that has defined the global tourism environment for a long time (Novelli et al., 2006). From a local perspective, the literature has highlighted the hidden potential for partnerships in building sustainable outcomes by adding relevance to local development strategies (Bramwell \& Lane, 1999; Aas et al., 2005; Hughes \& Scheyvens, 2018). In fact, cooperation, already considered as the key to successful and sustainable promotion a decade ago (Beritelli, 2011), boosts the tourism development (Wilson et al., 2001), and nowadays, the tourism sector is recognized to be 
featured by long-term collaborations among the actors (Frost and Laing, 2018).

Although the existing literature on tourism cooperation has referred to a comprehensive and sustainable promotion of the destination ${ }^{1}$, it lacks a deep investigation of the sustainable goals achieved through cooperation for destination promotion.

Also, a few studies referred to the extraordinary spread of digital technologies as one of the main means of the facilitation of cooperation to achieve sustainable benefits for a destination. Literature-usually considers cooperation as entailing long-term relationships: one of the main features of global markets (rational use of time) is too often underestimated. It relates to an agile management of time in hypercompetitive conditions, fostered through cooperation: this substantially influences the foundation of the cooperative relationship between partners.

By considering the relevance of both digital technologies and the use of time for the cooperation process to increase the destination's sustainable promotion, this study theorizes a model of temporary cooperation with a focus on the relationships occurring among local authorities. The intention is to borrow an existing model of temporary cooperation and to adapt it to the peculiarities of the present tourism industry with the support of an in-depth literature review. The model under consideration is the Virtual Enterprise (VE), originated first in the manufacturing industry during the nineties. It has also been widely used in different domains nowadays, as it represents a particular collaboration engaging selected partners for a short time around well-defined objectives, through the support of digital technologies as facilitators of the relationships between partners.

Theoretical foundation section refers to cooperation in tourism, highlighting the main features of cooperation in this industry, and offers an overview of the main contribution on VE model. The methodology section drives attention to the leading roles of four determinants for this model in tourism to be effective: information and communication technologies as condition sine qua non for the VE's existence (entailing both the organization and the operability); the destination management organization, having a pivotal role as promoter and coordinator; the short lifetime of the VE; and the overall promotion of the destination.

\footnotetext{
${ }^{1}$ According to Bornhorst, Ritchie, and Sheehan (2010) and Czernek (2013), cooperative behavior in tourism represents one of the main conditions for a region to achieve a competitive advantage.
} 


\section{Theoretical foundations}

\section{Cooperation in tourism}

The very term cooperation founds its origins in the Latin cooperatioonis, which derives from co-operari (www.treccani.it) basically, it means to operate with someone else: this definition underlies common aims for the parties that work together.

In tourism, the term refers to a voluntary, interactive process comprised of joint actions among autonomous stakeholders who engage resources and agree to follow shared rules, norms, and structures (Wood \& Gray, 1991; Czernek, 2013); in particular, the definition of Wood and Gray (1991) refers explicitly to several fundamentals of cooperation in tourism: parts are autonomous, they have a voluntary intention to join, they follow a common path while sharing defined rules. The definition also seemed to imply some underlying conditions, for instance a partner selection phase at the beginning, should already have occurred. It should also be noted that partners can cooperate around well-defined objectives, but remain autonomous so they can also compete around other aims (co-operation). Also, one or more common goals should drive the cooperative attitude toward an agreed-upon set of norms and rules, along with a mutual orientation (Wood \& Gray, 1991) and a set of common resources and capabilities dedicated and dispersed among partners (Bramwell \& Lane, 2000). In addition, power among partners should be evenly distributed. A formal plan of activities should be released, along with an intra-project and final checking phase to monitor compliance to initial collaborative decisions. Structures can take on different forms (Crotts, Buhalis, \& March, 2000; Fyall \& Garrod, 2005a), spanning from intra-sectoral relationships (if the partners come from within either the public or the private sectors) to inter-sectoral, when cooperation occurs between public and private sectors.

With a focus on the benefits for tourism partnerships, Bramwell and Lane (2000) consider collaborative advantage (mutual benefits) should be higher than competitive advantage in order to solicit partners to cooperate. The authors also suggest that mutual learning should be listed among the main benefits (thus, among the prominent determinants) for cooperation, as it seems to facilitate both concurrent learning and adaptive management. This confirms the willingness to cooperate, as determined by multiple advantages. Without a doubt, economic factors are the first, although not confined to a simple "costs and benefits" calculation; social and cultural factors are taken into consideration, too (Czernek, 2013). It must be noted that the same author considers a costs and benefits economic analysis essential to evaluating whether to enter a partnership.

Effective collaboration represents conditio sine qua non for tourism development success and seems to have some common features, such as: 
- the diversity of partners (Wood \& Gray, 2001; Waligo 2013), as cooperation can occur between government agencies, levels of administration, same-level policies, private and public sectors,

- trust (at cognitive and affective levels) among the involved stakeholders (Czakon \& Czernek, 2016),

- coordination activities (relating units or decisions), which are essential for achieving comprehensive destination development (Timothy, 1998), and

- power distribution among partners. In their work, Saito and Ruhanen (2017) distinguish four different power distribution models: coercive, legitimate, induced, and competent.

If both coordination and power distribution can affect the possibility of reaching the cooperation's aims (Beritelli, 2011), Novelli et al. (2006) states efforts between partners would decrease misunderstandings and conflicts related to overlapping goals. As cooperation can involve public authorities, local community, and tourism operators and businesses, it is considered that the community approach may be an effective way to develop and promote tourism. This would create the conditions necessary for intercommunity cooperation and collaboration, although it is a complex and difficult process to effectively put in place. For instance, local governments could be worried that developing tourism through collaboration could risk the loss of control over local decision-making (Huang \& Stewart, 1996; Jamal \& Getz, 1995). Because of these problems, research on collaboration and those factors that allow for community development of tourism is needed (e.g., Jamal \& Getz, 1995). Beritelli (2011) emphasized cooperation limits while considering three main categories: overexploitation of resources by the involved partners, the prisoner dilemma, and the challenge of collective action.

Cooperation could also affect local government in terms of the risk of losing control over local decision-making during collaboration (Huang \& Stewart, 1996; Jamal \& Getz, 1995). These limitations seem to entail, although not explicitly, long-term relationships among the partners involved. In reverse, we argue the same limits could be partially overcome through an emerging concept that fits the dynamic and unsteady features of global markets: the Virtual Enterprise (VE).

\section{The Virtual Enterprise}

The literature on alliances and cooperation has proliferated in several domains, and the manufacturing industry seemed to be the best point of observation for the partnerships for the huge recourse experienced in the area. In facing global markets, companies are continuously forced to rethink processes and market relationships due to the emerging relevance of time as a driver of competition. Due to the constraints determined by the global 
market features, the cooperative paradigm has evolved in recent years in response to the need for dynamic, adaptive relationships. The VE fits the need for a business to pursue cooperative advantages, but also feel free to join or exit at any time (Goel et al., 2010). More than one definition of VE exists. Among the first, Davidow and Malone (1992) consider the VE as an interfirm network, with a common aim of delivering a lower-cost, highervalue product than the supply chain as a whole can efficiently and quickly produce. Childe (1998) refers to an arising organizational paradigm of interfirm aggregations: a conceptual business unit or system that consists of a purchasing company and suppliers who collaborate closely in such a way as to maximize the returns to each partner. For Browne and Zhang (1999), a VE is a network with a specific aim, specific markets, and shared resources and costs.

One of the most recent, complete, and modern definitions of VE comes from Rabelo et al. (2016): a VE is a dynamic, temporary, and logical aggregation of autonomous, heterogeneous, and geographically dispersed enterprises that cooperate to better handle a given demand. The VE's operation is achieved via coordinated access over partners' competencies, resources, information, and knowledge, enabled by computer networks. Table 1 offers an overview of the main contribution of the VE.

Indeed, a clear, strong connection with information and communication technologies (Rabelo et al., 2004; Sari et al., 2007) has been a basic requirement for an effective VE since its original formulation, when computer networks and adequate IT tools and protocols 'support' cooperation (Camarinha-Matos et al., 1997). More recently, the use of communication and IT surges as one of the key characteristics of a VE (Camarinha-Matos \& Afsarmanesh, 2013). Thus, a virtual corporation represents a temporary network of independent companies (suppliers, customers, and even rivals) linked by IT, pursuing a business opportunity by sharing skills, costs, and access to one another's markets, or business processes business processes (Ouzounis \& Tshammer, 1999); the cooperative attitude dismantles as the business case ends, but the existence of the partners will continue independently (Camarinha-Matos et al., 2000).

Camarinha-Matos et al. (2000) underline two conditions sine qua non for VE to exist, in particular, to fit the global markets, the dynamism (agility), and the temporary nature. According to the authors, the first condition is a relevant requirement for successful organizations faced with market turbulence and unpredictable socio-economic changes, and depends both on the members' skills and supporting infrastructures. A few years later, Rabelo et al. (2004) refers to the concept of dynamic VE, focusing on time while presenting the search for implementing smart tools at lower costs and more effective ways, and speeding up the adaptation process. More recently, 
Goel et al. (2010) confirm the relevance of time while driving attention to the essential characteristics of a VE: purpose, lifetime (i.e., the VE is not formed to last over time), organizational structure, legal status, and customer interface.

For its relevance, time surges as one of the three main elements that qualify a VE: (1) the life cycle (Camarinha-Matos \& Afsarmanesh, 2013) (1) the contract (Ouzounis \& Tshammer, 1999), (2) the architecture (Goel et al., 2010). The contract refers to a pool of generic information (such as lifetime and start time), and other relevant information: rules, terms, services, and other features that qualify the VE (Ouzounis \& Tshammer, 1999); the concept of architecture concerns the VE's components (e.g., the system of human, tangible, or intangible resources that each partner devotes to the VE) and their relationship to each other.

Table 1. VE main features dispersed in the main contribution on topic

\begin{tabular}{|c|c|c|c|c|c|c|c|}
\hline & 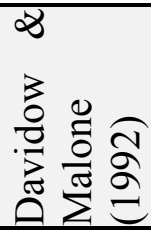 & 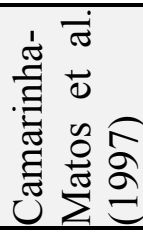 & 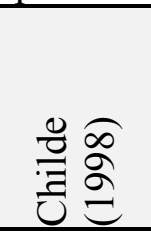 & 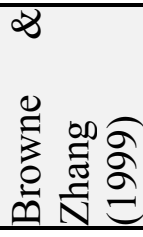 & 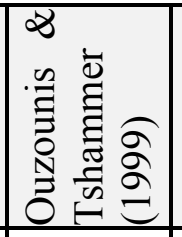 & 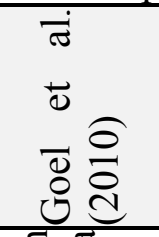 & 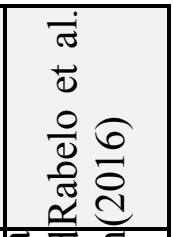 \\
\hline.$\Xi$ & 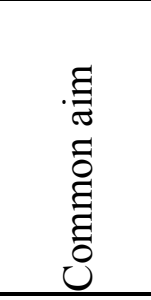 & 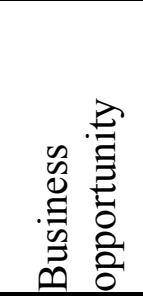 & 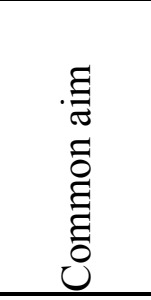 & 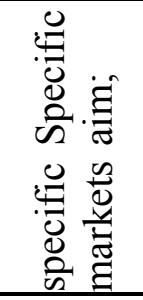 & 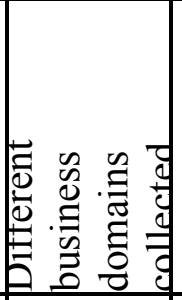 & 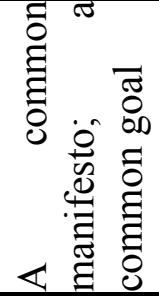 & 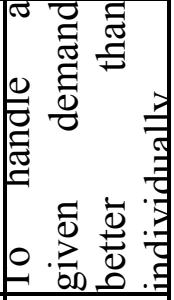 \\
\hline 苟 & & 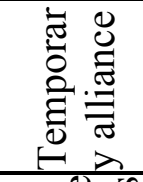 & & & & 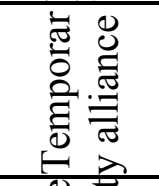 & 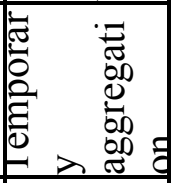 \\
\hline 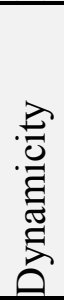 & & 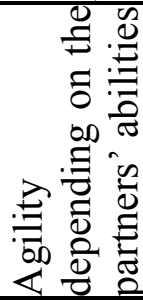 & & & & 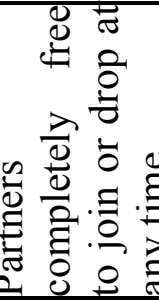 & 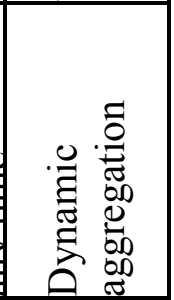 \\
\hline 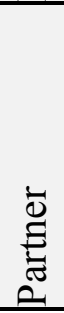 & & & 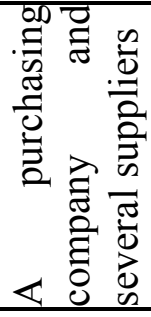 & & & & 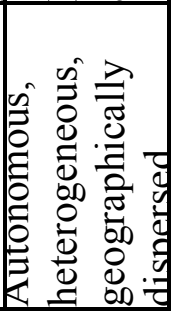 \\
\hline
\end{tabular}




\begin{tabular}{|c|c|c|c|c|c|c|c|}
\hline 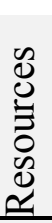 & 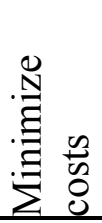 & 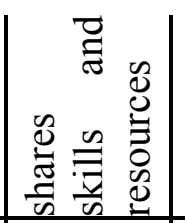 & & 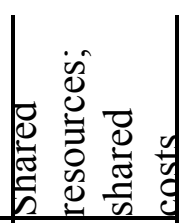 & 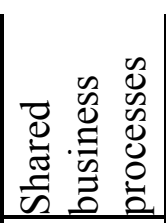 & & 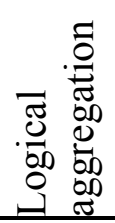 \\
\hline 营 & 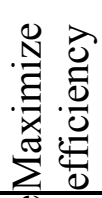 & & 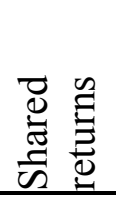 & & & 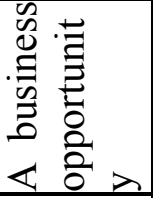 & \\
\hline 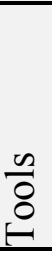 & 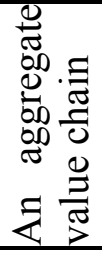 & 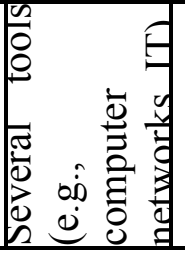 & & & & & \\
\hline
\end{tabular}

The VE architecture is essential, as not all of the skills, competencies, and resources that are part of the partners' architectures are brought into the VE. Thus, the VE's components are only the ones dedicated to the temporary alliance (Goel et al., 2010).

Finally, the creation and development of a VE seems to pass through a sequence of elements and phases, very similar to a life cycle (e.g., creation, operation, and dissolution) (Klen et al., 1998). Several authors have considered the VE life cycle as representative of the whole VE existence. Similar to Klen et al. (1998), the model proposed by Ouzounis and Tshammer (1999) categorized the actions taken by the partners into three main categories:

- Establishment phase: establishment and configuration of the linkage between partners, including the initial negotiations to agree on a specific set of business process interfaces that will be provided by the partners under certain conditions (such as security, reliability, authentication, payment, and fault tolerance).

- Provision phase: the provided services can be accessed and invoked in a secure and modest way by the VE's members.

- Termination phase: the access rights, interfaces, and implementations of the provided business processes and services that can be modified by the VE's partners.

Later on, Camarinha-Matos and Afsarmanesh (2013) released the four-stages life cycle model, as a VE evolution is considered the result of the dynamic management of a collaborative decision.

In fact, there is recognition of the need to properly handle decisions and solutions relative to the number of unexpected problems (and 
opportunities) that could appear during the operation phase in order to achieve the VE's aims (Drissen-Silva et al., 2009).

Table 2. Summary of different characteristics of VE and other paradigms

\begin{tabular}{|c|c|c|c|}
\hline & Interfirm Network & Extended Enterprise & Virtual Enterprise \\
\hline 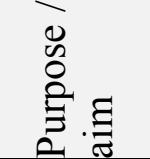 & $\begin{array}{l}\text { Increase } \\
\text { competitiveness }\end{array}$ & $\begin{array}{l}\text { Seamlessly integrate } \\
\text { external } \\
\text { entities/partners }\end{array}$ & $\begin{array}{l}\text { Exploit a specific } \\
\text { business } \\
\text { opportunity }\end{array}$ \\
\hline 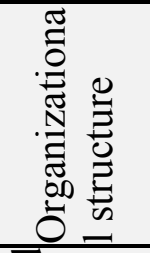 & $\begin{array}{l}\text { Differs depending } \\
\text { on cases }\end{array}$ & $\begin{array}{l}\text { Controlled by a main } \\
\text { participating enterprise } \\
\text { that 'extends' its } \\
\text { boundaries vertically in } \\
\text { the value chain }\end{array}$ & $\begin{array}{l}\text { Controlled by a } \\
\text { common goal and } \\
\text { manifesto }\end{array}$ \\
\hline 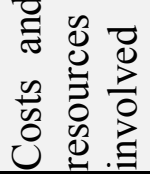 & $\begin{array}{l}\text { Direct and indirect } \\
\text { (HR, knowledge, } \\
\text { infrastructures) }\end{array}$ & $\begin{array}{l}\text { Moderate to low cost, } \\
\text { labor related. Mainly } \\
\text { indirect }\end{array}$ & $\begin{array}{l}\text { Low cost, labor } \\
\text { related. } \\
\text { indirect }\end{array}$ \\
\hline 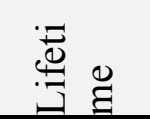 & $\begin{array}{ll}\text { Long term and } \\
\text { stable }\end{array}$ & Long term and stable & $\begin{array}{l}\text { Ad-Hoc and } \\
\text { temporary }\end{array}$ \\
\hline 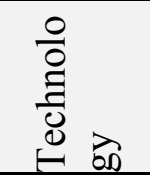 & $\begin{array}{l}\text { Not } \\
\text { connected }\end{array}$ & Not directly connected & $\begin{array}{l}\text { Necessary to make } \\
\text { it effective }\end{array}$ \\
\hline 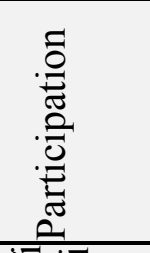 & $\begin{array}{l}\text { Participants may } \\
\text { join the network } \\
\text { exclusively }\end{array}$ & $\begin{array}{l}\text { Participants may join } \\
\text { EE exclusively }\end{array}$ & $\begin{array}{l}\text { Participants may } \\
\text { join or drop any } \\
\text { time, and may } \\
\text { involve multiple } \\
\text { VEs at same time } \\
\end{array}$ \\
\hline 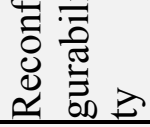 & Low & Low & Very high \\
\hline 胥 & Moderate & Moderate & Very high \\
\hline 离 & High & Moderate & Low and temporary \\
\hline
\end{tabular}


A deeper investigation of the VE main features emerges by comparing two well-known concepts: the interfirm network and the extended enterprise, as summarized in Table 2.

\section{Methodology}

This section describes the concept of VE as adapted to the peculiarities of tourism, following the aim of the comprehensive development of tourism, and by mixing a systematic literature review on temporary cooperation with the main features of tourism' cooperation. The study considers the destination similar to Fyall et al. (2005b): a mixed entity made of a system of components that can work with or against one another. Therefore, collaboration is considered as a natural response and one of the few practical strategies that can be used for the destination's comprehensive development (Wang, 2008). The destination works as a complex system of independent actors, in which the government should confine its role: Van der Zee and Vanneste (2015) state authorities' roles as facilitators of the relationship between actors (Chim-miki \& Batista-Canino, 2017) and coordinators of the parts involved (i.e., economic and social agents) (MeliánGonzález \& García-Falcón, 2003).

Following this idea, the VE model for tourism is built by considering the simplified four-stage life cycle model suggested by Camarinha-Matos and Afsarmanesh (2013) as the starting point, distinguishing creation, operation, evolution, and dissolution (see Fig. 1).

Their work seems to bypass the theory of Ouzounis and Tshammer (1999), who categorized the actions taken by the partners into the basic three phases of establishment, provision, and termination, as the dynamic use of time seems not even implicitly considered. Both the three-stages and the four-stages model focuses attention around the first of two main features of VEs (Rabelo et al., 2016), the relevance of time for VEs: as this form of cooperation exists for a short-term life span, the dissolution phase is consciously listed. The second main feature is high reconfigurability, fitting into the global markets using optimal methods, and meeting high turbulence levels (dynamicity): but this only emerges through the four stages model.

For this reason, the three-stages model can be widely adapted to almost all situations, nevertheless the basic schema presented by CamarinhaMatos and Afsarmanesh (2013) can fit the best the VE in tourism. 


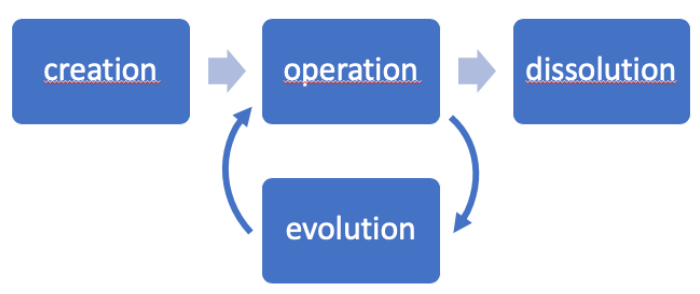

Fig. 1. The four stage of a virtual enterprise life cycle (Camarinha-Matos \& Afsarmanesh, 2013)

As the four stages model was first elaborated almost a decade ago, a deeper analysis could be of further support due to the global markets fast changes, and for the particular features of the industry under examination.

In the model hereafter suggested, a focal role is clearly attributed to the destination management organization as the promoter of the entire life cycle. The destination management organization (DMO) should be responsible for every stage, which is confirmed by the above-mentioned theory of van der Zee and Vanneste (2015). Also, the aim of the VE, when the destination management organization plays a central role, should be directly related to a joint, inclusive, and comprehensive promotion of the destination - as entailed by the heading of the DMO.

Further detailing the four stages lifecycle into a nine-stage life cycle model could offer an effective path for the VE operability, with an explicit leading role to dynamic change. Presented in Table 3, the proposed life cycle is still clearly related to the four main stages. New opportunities are also added in the ninth stage, as it is assumed that at the end of the VE's lifetime, partners could decide to dissolve it, continue working together by extending the VE's lifetime, create a new (similar or partially different) VE, or even establish a different, long-term alliance. This stress the idea of dynamic change.

This suggests a possible evolution of the VE to a different kind of cooperation, one that is steady and long-lasting, or to a new VE (see Fig. 2). These further possibilities of keeping the cooperation alive provide a possible explanation of the VE generating as a first, tentative collaborative project; a sort of test before the partners decide to cooperate in a more permanent and structured way. 
Table 3. The VE life cycle in tourism

\begin{tabular}{|c|c|c|}
\hline $\begin{array}{l}\text { Three-stages } \\
\text { model } \\
\text { (Ouzounis \& } \\
\text { Tshammer, } \\
\text { 1999) }\end{array}$ & \begin{tabular}{|ll} 
Four-stages & \\
model & \\
(Camarinha- & \\
Matos & $\&$ \\
Afsarmanesh, & \\
2013)
\end{tabular} & Nine-stages life cycle model \\
\hline \multirow{3}{*}{$\begin{array}{l}\text { Establishment } \\
\text { phase }\end{array}$} & \multirow{3}{*}{ Creation } & $\begin{array}{l}\text { 1. Common aim } \\
\text { (purpose) }\end{array}$ \\
\hline & & 2. Partner selection \\
\hline & & 3. Resources attribution \\
\hline \multirow{4}{*}{ Provision phase } & \multirow[t]{2}{*}{ Operation } & $\begin{array}{l}\text { 4. Collaborative VE planning (timing, } \\
\text { milestones) }\end{array}$ \\
\hline & & 5. Operation of the VE \\
\hline & \multirow[b]{2}{*}{ Evolution } & 6. In-process check \\
\hline & & $\begin{array}{l}\text { 7. In-process } \\
\text { collaborative VE planning }\end{array}$ \\
\hline \multirow[b]{2}{*}{$\begin{array}{l}\text { Termination } \\
\text { phase }\end{array}$} & \multirow{2}{*}{$\begin{array}{l}\text { Termination and } \\
\text { dissolution }\end{array}$} & 8. Achievement of the common aim \\
\hline & & $\begin{array}{l}\text { 9. Dissolution of the } \mathrm{VE} \text { or further } \\
\text { evolution to a new } \mathrm{VE} / \text { cooperation }\end{array}$ \\
\hline
\end{tabular}

The starting point of the VE should be the identification of a specific promotional opportunity by the destination management organization that is in charge of performing a SWOT analysis (strengths, weaknesses, opportunities, and threats).

Such opportunities should range from common communication projects to more focalized marketing projects (e.g., the promotion of wine routes or religious tourism paths that consider the whole destination).

Fig. 2. The suggested VE life cycle

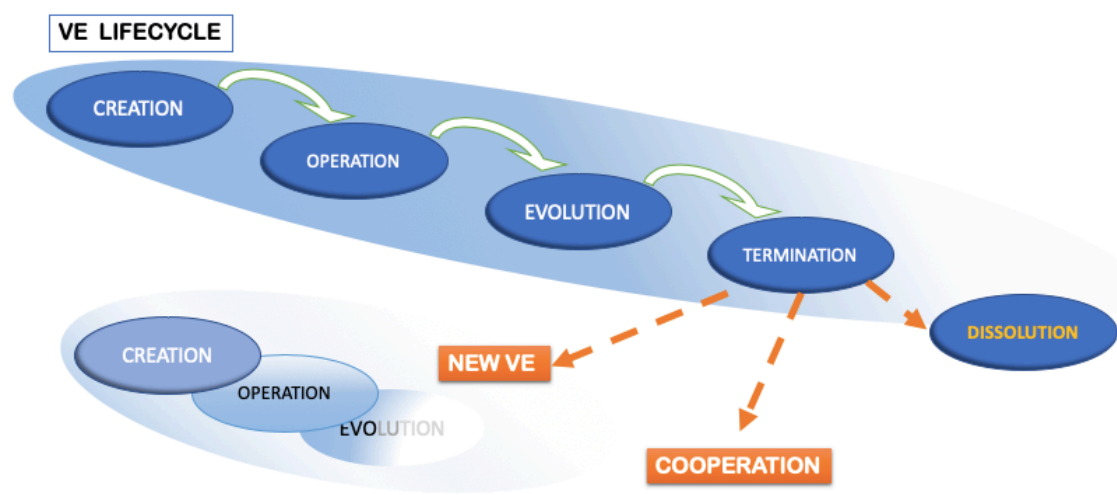


As it is developed in global markets, the VE entails the use of information and communication technologies as the basis of making the VE effective, while reducing time and supporting the rational use of resources that each partner has to devote to the project. The main driver for identifying the VE's purpose for the destination management organization is subject to the comprehensive development of the destination. This implies as first that the destination is not a unicum: the project should take into account - and give value to - the subareas' main features, while promoting the whole.

As a second, the comprehensive development of the destination should influence the main criterion to use in partner selection: the representativeness of the whole destination. This serves to legitimize the destination management organization's operation as VE promoter and leading subject. Every partner remains completely independent (confirming the hypothesis that the actors work in a coopetitive tourism environment); thus, the destination should be supported by the VE on a non-exclusive basis. Partner selection should also take into account the resources and time every partner could dedicate to the common project. Information, materials, and HR work needs to be shared, coordinated, and exchanged for mutual improvement. Advertising activities should be scheduled and planned.

Table 4. Main features of a VE in tourism

\begin{tabular}{|l|l|}
\hline Purpose & $\begin{array}{l}\text { Exploit a specific business opportunity for joint, } \\
\text { comprehensive promotion of the destination }\end{array}$ \\
\hline $\begin{array}{l}\text { Partners } \\
\text { selection }\end{array}$ & $\begin{array}{l}\text { Destination management organization plays a pivotal } \\
\text { role } \\
\text { Should be representative of the whole destination for } \\
\text { comprehensive development }\end{array}$ \\
\hline $\begin{array}{l}\text { Participation } \\
\text { Dependency }\end{array}$ & $\begin{array}{l}\text { Participants may join or drop at any time and may be } \\
\text { involved in multiple VEs at the same time }\end{array}$ \\
\hline $\begin{array}{l}\text { Organizational } \\
\text { structure }\end{array}$ & $\begin{array}{l}\text { Low, limited to shared resources and declared } \\
\text { commitment } \\
\text { requires a formal business plan } \\
\text { defined Activities should be planned and timing should be } \\
\text { serve as facilitator and coordinator }\end{array}$ \\
\hline Lifetime & \begin{tabular}{l} 
Ad-hoc and temporary; depends on the VE's purpose \\
\hline
\end{tabular}
\end{tabular}




\begin{tabular}{|c|c|}
\hline $\begin{array}{l}\text { Costs and } \\
\text { Resources } \\
\text { involved }\end{array}$ & $\begin{array}{l}\text { Low cost, labor related. } \\
\text { Mainly indirect }\end{array}$ \\
\hline Technology & $\begin{array}{l}\text { Necessary to make it effective: } \\
\text { 1. } \quad \text { For intra-VE connection } \\
2 . \quad \text { For the VE's activities }\end{array}$ \\
\hline Reconfigurability & Very high; in-process adjustments \\
\hline
\end{tabular}

Collaborative VE planning should be prepared and shared before the VE's activities start. A common project should be approved by the partners, but represent the best tools in order to clearly plan the entire project. The project should also consider the timing of the activities, as it affects the achievement of the VE's goal. The in-process check should be performed in order to update partners about the state of goal achievement, and an ongoing check should be considered to adjust the VE's operation and plan. The inprocess check represents a fundamental stage and is considered an opportunity for improving the project to achieve the VE's aim better and faster, if possible. The in-process control mechanism should be considered in the initial planning, leaving space for improvements to the deployment of subsequent milestones.

\section{Discussion of results}

Cooperation is widely considered as a way for businesses to reduce the highly competitive pressures faced in global markets. Through systematic relationships, two or more independent entities work together to pursue a common aim and gain a competitive advantage. Cooperation is a relevant opportunity for businesses, tourism operators, and authorities to widen global market presence, and the literature and empirical analysis have developed the concept around the particular features of the tourism industry.

Nowadays, global market features highlight the relevance of a competitive management of time while cooperating, and a dynamic use of time surges as a competitive behavior driver, both for running companies and cooperation. Temporary cooperation models seem to be especially fitting the manufacturing industry features, supported by the literature developed so far on topic, nevertheless it is also true for - and widely adopted in - the tourism'. This work offered a dynamic, short-time perspective on cooperation, introducing a concept already in use for manufacturing entities and other industries: the VE, a particular kind of cooperation entailing shorttime that highly emphasizes the use of information and communication technologies. The idea of temporary cooperation has found support in the 
literature over the last few decades, expressing as the need to continuously adapt and strengthen in response to turbulent, highly unsteady, competitive environments. Despite is applicability, the tourism domain lacks contributions specifically dedicated to this form of cooperative engagement so far.

In this paper, the VE concept was developed in a well-defined model - fit to the tourism industry and tailor-made to cooperation among local authorities. By adapting the main features of the VE to tourism through a systematic literature review, two theories on the VE life cycle are mainly considered as the basis for a nine-stage life cycle model. The main features of this model were provided in a dedicated table, outlining the temporary, dynamic, and common aim for the comprehensive development of the destination.

The achievement of the common aim is considered as a condition sine qua non for the VE's existence. This confirms the examined theories, as the VE will dismantle and the partners' involved resources will be freed up when the VE's aim has been achieved, or when the planned VE's lifetime has expired. If dissolution seems to be related to the aim's achievement or the conclusion of a given lifetime, sometimes the VE also dismantles because of a common partner decision, regardless of whether the aim is achieved. Further evolution of the VE could also emerge, suggesting the possibility for the VE to become a steadier and long-lasting cooperation. In order to make the VE effective and efficient, four conditions for emerge (see Fig. 3):

- The destination management organization has a pivotal role and represents the head of the VE.

- Time is a core condition: the VE engages a short-term commitment around a well-defined aim or a given VE lifetime is planned. Also, high reconfigurability stress the idea of fast, dynamic change both during the development and the termination stages.

- Information and Communication Technologies (ICTs) enable and facilitate the VE's structural system and boosts its ability to operate fast and dynamically.

- The destination needs to be considered in a comprehensive manner to validate the destination management organization's legitimacy, and to expand its advantages.

The pivotal role of the destination management organization's commitment to the overall development of promotion was also emphasized. The importance of the partners' independence was stressed, as common resources devoted to pursuing the VE's aim are limited. 


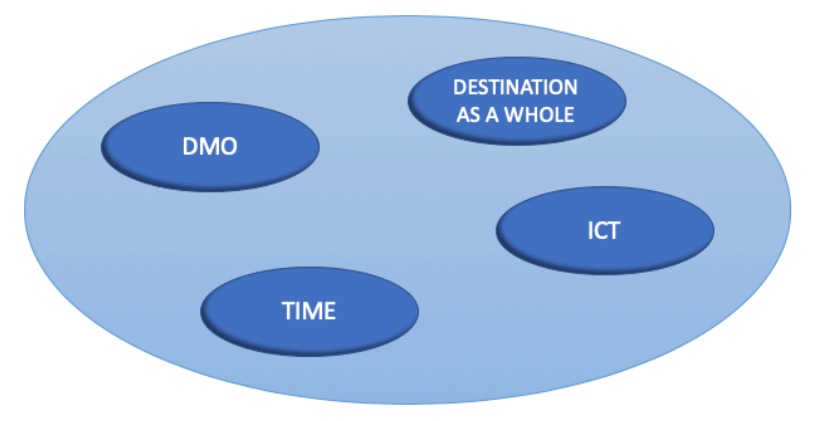

Fig. 3. Conditio sine qua non for VE effectiveness

Furthermore, since information and communication technologies have become essential in daily life, this was also true for the functioning of the VE. These technologies worked both as facilitators for partners' relationships and as tools for accomplishing single partner's VE requirements. The suggested model could provide a new effective and sustainable way for destination managers to overcome their systematic lack of resources, and to achieve benefits from partnering while not being forced into long-lasting relationships.

\section{Limitations and future research}

This work has offered a theoretical schema and an interpretation model for achieving superior tourism advantages for a destination, while supporting the local destination management organization and soliciting its pivotal role. As a limitation, the work does not offer an empirical analysis at this stage. Thus, to support the elaborated theoretical model, an empirical case should be provided. Through examination, the case should validate the short-time life cycle of the VE, along with its main features, condition sine qua non for the development of the suggested type of VE; a conjoint, comprehensive development of the destination under examination achieved with digital tools.

Further in-depth analysis should also be performed to validate the VE model as elaborated on a broader scale. Accordingly, further research should be devoted to checking the model's validity in other similar cases to stress the idea of VEs in the tourism domain. Also, the model requires the destination management organization to function as partner and head of the project. While the VE should not be confined to partnering with public authorities, this could ensure a comprehensive development for the destination. Therefore, it could be of interest to check the model's validity for tourism promotion while changes occur in the model's fundamentals, 
particularly when the destination management organization does not serve as partner for the project.

\section{References:}

1. Aas, C., Ladkin, A. and Fletcher J. (2005) 'Stakeholder collaboration and heritage Management' Annals of Tourism Research, 32 (1) 28-48

2. Beritelli, P. (2011). Cooperation among prominent actors in a tourist destination. Annals of Tourism Research, 38(2), 607-629.

3. Bornhorst, T., Ritchie, B., \& Sheehan, L. (2010). Determinants of tourism success for DMOs and destinations: An empirical examination of stakeholders'perspectives. Tourism Management, 31(5), 572-589

4. Bramwell B., and Lane B. (Eds., 2000), Tourism Collaboration and partnerships. politics, practice and sustainability (pp. 200-230). Clevedon: Chanel View Publications

5. Bramwell, B., and Lane, B. (1999). Collaboration and partnerships for sustainable tourism. Journal of Sustainable Tourism, 7(3and4), 274-289.

6. Browne, J., \& Zhang, J. (1999). Extended and virtual enterprisessimilarities and differences. International journal of agile management systems.

7. Camarinha-Matos, L. M., Afsarmanesh, H., \& Rabelo, R. (2000, December). Supporting agility in virtual enterprises. In Working Conference on Virtual Enterprises (pp. 89-104). Springer, Boston, MA.

8. Camarinha-Matos, L. M., Afsarmanesh, H., and Ollus, M. (2005, September). ECOLEAD: A holistic approach to creation and management of dynamic virtual organizations. In Working Conference on Virtual Enterprises (pp. 3-16). Springer, Boston, MA.

9. Camarinha-Matos, L. M., and Afsarmanesh, H. (Eds.). (2013). Infrastructures for Virtual Enterprises: Networking Industrial Enterprises IFIP TC5 WG5. 3/PRODNET Working Conference on Infrastructures for Virtual Enterprises (PRO-VE'99) October 27-28, 1999, Porto, Portugal (Vol. 27). Springer.

10. Childe, S. J. (1998). The extended concept of cooperation. Production planning \& control, 9(4), 320-327.

11. Chim-Miki A.F., Batista-Canino R. M., 2017, Tourism coopetition: An introduction to the subject and a research agenda, International Business Review, n.26, p. 1208-1217

12. Crotts, J. C., Buhalis, D., and March, R. (2000). Introduction: Global alliances in tourism and hospitality management. International Journal of Hospitality and Tourism Administration, 1(1), 1-10. 
13. Czakon, W., \& Czernek, K. (2016). The role of trust-building mechanisms in entering into network coopetition: The case of tourism networks in Poland. Industrial Marketing Management, 57, 64-74.

14. Davidow, W. H. (1992). The virtual corporation: Structuring and revitalizing the corporation for the 21 st century.

15. Drissen-Silva, Marcus Vinicius, and Ricardo J. Rabelo. "A collaborative decision support framework for managing the evolution of virtual enterprises." International Journal of Production Research 47.17 (2009): 4833-4854.

16. Frost, W., and Laing, J. (2018). Public-private partnerships for nature-based tourist attractions: the failure of Seal Rocks. Journal of Sustainable Tourism, 26(6), 942-956.

17. Fyall, A., and Garrod, B. (2005a). From competition to collaboration in the tourism industry. Global tourism, 4, 54-72.

18. Fyall, A., and Garrod, B. (2005b). Tourism marketing: A collaborative approach (Vol. 18). Channel View Publications.

19. Garbelli M., 2014, Performance measurement and global networks, Giappichelli ed.

20. Goel, A., Schmidt, H., \& Gilbert, D. R. (2010, December). Formal Models of Virtual Enterprise Architecture: Motivations and Approaches. In PACIS (p. 117).

21. Huang, Y. H., and W. P. Stewart (1996). "Rural Tourism Development: Shifting Basis of Community Solidarity." Journal of Travel Research, 34 (Spring): 26-31.

22. Hughes, E., Scheyvens, R. (2018). Development Alternatives in the Pacific: How Tourism Corporates Can Work More Effectively with Local Communities. Tourism Planning \& Development, 15(5), 516534.

23. Jamal, T. B., and D. Getz (1995). Collaboration theory and community tourism planning. Annals of Tourism Research, 22 (1): 186-204

24. Novelli, M., Schmitz, B., and Spencer, T. (2006). Networks, clusters and innovation in tourism: A UK experience. Tourism management, 27(6), 1141-1152.

25. Olsen, L. S. (2016). Sami tourism in destination development: conflict and collaboration. Polar Geography, 39(3), 179-195.

26. Ouzounis, V., \& Tschammer, V. (1999, January). A framework for virtual enterprise support services. In Proceedings of the 32nd Annual Hawaii International Conference on Systems Sciences. 1999. HICSS32. Abstracts and CD-ROM of Full Papers (pp. 9-pp). IEEE. 
27. Rabelo, R. J., Baldo, F., Alves-Junior, O. C., and Dihlmann, C. (2016). Virtual enterprises: strengthening SMES competitiveness via flexible businesses alliances. In Competitive Strategies for Small and Medium Enterprises (pp. 255-272). Springer, Cham.

28. Rabelo, R. J., Baldo, F., Tramontin, R., Pereira-Klen, A., and Klen, E. R. (2004, August). Smart configuration of dynamic virtual enterprises. In Working Conference on Virtual Enterprises (pp. 193204). Springer, Boston, MA.

29. Saito, H., and Ruhanen, L. (2017). Power in tourism stakeholder collaborations: Power types and power holders. Journal of Hospitality and Tourism Management, 31, 189-196.

30. Sari, B., Sen, T., and Kilic, S. E. (2007). Formation of dynamic virtual enterprises and enterprise networks. The International Journal of Advanced Manufacturing Technology, 34(11-12), 1246-1262.

31. Timothy, D. J. (1998). Co-operative tourism planning in a developing destination. Journal of Sustainable Tourism, 6(1), 52-68

32. van der Zee, E., Vanneste, D. (2015). Tourism networks unravelled; a review of the literature on networks in tourism management studies. Tourism Management Perspectives, 15, 46-56.

33. Wang, Y. (2008). Collaborative destination marketing: Understanding the dynamic process. Journal of travel Research, 47(2), 151-166.

34. Wang, Y., and Fesenmaier, D. R. (2007). Collaborative destination marketing: A case study of Elkhart county. Indiana. Tourism Management, 28(3), 863-875.

35. Wilson, S., Fesenmaier, D. R., Fesenmaier, J., and Van Es, J. C. (2001). Factors for success in rural tourism development. Journal of Travel research, 40(2), 132-138.

36. Wood, D. J., and Gray, B. (1991). Toward a comprehensive theory of collaboration. Journal of Applied Behavioral Science, 27(2), 139-162

37. Melian-Gonzalez, A., \& García-Falcón, J. M. (2003). Competitive potential of tourism in destinations. Annals of Tourism Research, 30(3), 720-740. 